\title{
$8^{\circ}$ Encontro da Divisão de Catálise e Materiais Porosos da SPQ
}

O $8^{\circ}$ Encontro Nacional de Catálise e Materiais Porosos (8ENCMP) da Sociedade Portuguesa de Química decorreu em Lamego, de 21 a 23 de Setembro de 2007. A Comissão Organizadora do Encontro foi constituída por docentes e colaboradores do Departamento de Química da Universidade de Coimbra, e presidida pela Professora Mariette Pereira.

O programa científico incluiu quatro conferências plenárias e quatro comunicações convidadas, 16 comunicações orais e 56 comunicações em poster, e terminou com um debate sobre Perspectivas para a Catálise. Estas actividades foram complementadas com um rico e variado programa social, incluindo um passeio de barco no rio Douro, que proporcionou amplas oportunidades para contactos e discussões informais. O sucesso deste Encontro é comprovado pelo elevado número de participantes nacionais e estrangeiros, cerca de 130. Durante o Encontro foi ainda atribuído um prémio simbólico, oferecido pela Universidade de Coimbra, aos investigadores nacionais que em 2005 foram seleccionados como candidatos da DCMP ao prémio FisoCat 2005.

No final do Encontro realizou-se a reunião da Divisão de Catálise e Materiais Porosos da Sociedade Portuguesa de Química, tendo como objectivo eleger os corpos directivos para o biénio 2007-2009 e as correspondentes representações internacionais:

- Presidente da Divisão de Catálise e Materiais Porosos: Joaquim Faria (FEUP)

- Representante na FEZA (Federação das Associações Europeias de Zeólitos): Filipa Ribeiro (IST)

- Representantes na IACS (Associação Internacional das Sociedades de Catálise): Joaquim Faria (FEUP) e Isabel Fonseca (UNL)

- Representantes na EFCATS (Federação Europeia das Sociedades de Catálise): Fernando Ramôa Ribeiro (IST) e Joaquim Faria (FEUP)

- Representantes na FisoCat (Federação Ibero-Americana de Sociedades de Catálise): Mariette Pereira (UC) e
Joaquim Faria (FEUP)

Foram ainda prestadas informações sobre prémios internacionais e sobre o IX Congresso Europacat.

O prémio FisoCat para investigadores júnior e sénior será atribuído durante o XXI Simpósio Ibero-Americano de Catálise (http://www.sicat2008.es/), que se realiza em Málaga de 22 a 27 de Junho de 2008. Os interessados neste prémio devem candidatar-se até 15 de Janeiro de 2008.

O prémio FEZA (http://www.feza-online.org/fezaprice.html) será atribuído ao melhor trabalho de Doutoramento na área dos zeólitos durante a $4^{\mathrm{a}} \mathrm{Con}$ ferência Internacional FEZA (http:// www.congres.upmc.fr/feza2008/), que se realiza em Paris de 2 a 6 de Setembro de 2008.

O IX Congresso Europacat vai realizar-se em Salamanca em 2009, e será organizado conjuntamente pela Sociedade Espanhola de Catálise e pela Sociedade Portuguesa de Química.

J.L. Figueiredo

\section{7a Conferência de Química Inorgânica (7ConfQI)}

Realizou-se nos dias 30 de Novembro e 1 de Dezembro a $7^{a}$ Conferência de Química Inorgânica, numa organização presidida pela Profa Cristina Freire do Departamento de Química da FCUP. Este encontro, que decorreu no Hotel Centenário em Fátima, contou com cerca de 80 participantes. O programa científico incluiu 6 Plenárias, 17 comunicações orais e 72 comunicações em poster.

Os temas das várias contribuições incluíram quer aspectos mais "puros", de síntese e caracterização de novos compostos e de cálculos teóricos, quer o desenvolvimento de novos materiais funcionais em áreas de interface, no- meadamente, nas áreas do magnetismo, óptica e biologia/medicina.

É de salientar que a última sessão do dia 30 de Novembro foi dedicada ao Prof. Alberto Romão Dias. Houve intervenções de antigos alunos e colaboradores que deram o seu testemunho da dimensão humana e científica do Prof. Romão Dias. Houve depois um conjunto de 3 apresentações orais de colaboradores que integram - CQE-IST que abordaram as várias facetas da actividade científica desenvolvida no seio do grupo de investigação liderado pelo "Chefe". Foi, no final desta sessão, apresentada uma petição para ser entregue ao Conselho
Directivo da SPQ para que se institua um Prémio Prof. Alberto Romão Dias na área da Química Inorgânica.

No final do encontro foi eleito o Prof. Tito Trindade da Universidade de Aveiro como novo presidente da Divisão de Química Inorgânica da SPQ para o biénio 2007-2009, assumindo a responsabilidade de organizar a $8^{a}$ Conferência de Química Inorgânica. 